\title{
ESTUDO DA ESTABILIDADE DE ANTOCIANINAS EXTRAÍDAS DOS FRUTOS DE AÇAÍ (Euterpea oleracea Mart.)
}

\author{
Z. G. $\operatorname{COSTA}^{1 *}$, C. L. O. C. $\operatorname{SILVA}^{2}$, C. M. L. $\operatorname{COSTA}^{2}$ e L. J. G. FARIA ${ }^{2}$ \\ ${ }^{1}$ Universidade Federal do Pará, ITEC, Faculdade de Engenharia Química \\ ${ }^{2}$ Universidade Federal do Pará, Programa de Pós-Graduação em Engenharia Química \\ *e-mail: zizagc_ufpa@hotmail.com
}

\begin{abstract}
RESUMO
O açaí, como é conhecido o fruto do açaizeiro (Euterpe oleracea Mart.), produz uma bebida de grande valor nutricional e consumida em todo o mundo. Porém, o fruto apresenta também aplicação industrial como corante natural a partir da extração de antocianinas responsáveis pela sua forte coloração. Tendo-se em vista a crescente demanda da indústria por corantes de origem natural em detrimento àqueles sintetizados artificialmente, estuda-se a estabilidade do extrato antociânico quando exposto à degradação luminosa com base em dados experimentais obtidos em câmaras luminosas. Utilizou-se de lâmpadas fluorescente $(15 \mathrm{~W})$, incandescente $(60 \mathrm{~W})$, LED (5 W) e infravermelho $(250 \mathrm{~W})$, tendo-se como padrão uma amostra mantida no escuro, protegida da luz. São utilizados como parâmetros de monitoramento da estabilidade a caracterização dos extratos pelo teor de antocianinas e parâmetros colorimétricos (Hunter Lab). Através das análises experimentais pode ser verificado vários fatores influentes na degradação do corante e foi evidenciado que a luz teve importância fundamental nesta degradação, pois reduziu o tempo de meia vida do extrato analisado.
\end{abstract}

\section{INTRODUÇÃO}

O açaizeiro (Euterpe oleracea Mart.) é uma Arecaceae típica da região norte do Brasil, cujos frutos são caracteristicamente pequenos, arredondados e de coloração roxoescuro (SOUSA et al., 2006). Foi observado nos últimos anos um crescimento de demanda no mercado nacional pelos derivados do fruto de açaí, despertando grande interesse em investimentos e pesquisas sobre o assunto. Este aumento pode ser atribuído às propriedades nutricionais do açaí, e por possuir um elevado teor de pigmentos chamados antocianinas, que, dentre outras características, são benéficos à saúde (ALEXANDRE, CUNHA e HUBINGER, 2004).
Corantes são adicionadas em determinados produtos, principalmente para restituir a aparência original (afetada durante as etapas de processamento, estocagem, embalagem e distribuição) e para torná-lo visivelmente atraente. Os corantes advindos do açaí têm muitas vantagens, porém a principal desvantagem está no elevado custo de produção, e na baixa estabilidade a luz, temperatura e $\mathrm{pH}$ quando comparados aos corantes artificiais (MELO, COSTA e FARIA, 2001).

Geralmente, a medição de antocianinas é feita por análise espectrofotométrica. Esta técnica não reflete a cor quando mede a absorvância de um extrato num particular comprimento de onda, além de ser demorada. Por outro lado, a cor visível, que é um indicativo da concentração do pigmento, pode 
ser medida instantaneamente usando colorímetros Hunter para controle de qualidade on-line (KARA e ERÇELEBI, 2013).

Desta forma, este trabalho visa investigar o efeito de diferentes tipos luz sobre a deterioração de corantes contidos nos frutos de açaí, estudando a cinética de antocianinas e os parâmetros Hunter de cor (L, a e b) em extratos líquidos. Além de propor modelos para a taxa de fotodegradação com o tempo, em função do tipo de luz empregada.

\section{MÉTODOS}

O trabalho foi conduzido no Laboratório de Corantes (LabCor), locado na FEQ/UFPA, utilizando frutos inteiros e frescos de açaí proveniente do município do Acará, Estado do Pará. Os frutos foram coletados em outubro de 2014 e armazenados em freezer convencional a $-18{ }^{\circ} \mathrm{C}$ e após 50 dias foram submetidos ao procedimento de extração do extrato antociânico.

Os reagentes químicos utilizados neste trabalho foram todos de grau analítico.

Estes extratos foram obtidos segundo metodologia descrita por Constant (2003). Macerou-se o fruto em etanol $70 \%$ acidificado a $\mathrm{pH} 2,0$ com $\mathrm{HCl}$ durante $48 \mathrm{~h}$ ao abrigo da luz, em temperatura ambiente $\left(30^{\circ} \mathrm{C}\right)$, realizando posterior filtração em papel Whatman 1.

O extrato foi distribuído em porções de $20 \mathrm{~mL}$ (porção de extrato utilizada na análise colorimétrica) e $10 \mathrm{~mL}$ (porção de extrato utilizada na análise de teor de antocianinas) em tubos de ensaio vedados com filme plástico. Estes colocados em quatro câmaras de fotodegradação (Figura 1) contendo lâmpadas fluorescente $(15 \mathrm{~W})$, incandescente $(60 \mathrm{~W})$, LED (5 W) e infravermelho $(250 \mathrm{~W})$.

Verificou-se a degradação dos compostos bioativos durante um período de observação de 30 dias, as primeiras cinco medições foram feitas em intervalos de $12 \mathrm{~h}$, após isto, uma medição foi feita em intervalo de $24 \mathrm{~h}$ seguida de treze medições em intervalos de $48 \mathrm{~h}$. Totalizando 672 horas de observação.

Figura 1 - Câmara de Fotodegradação.

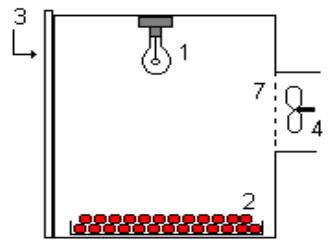

a) Vista Latera

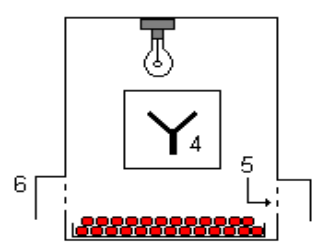

b) Vista Frontal
Fonte: CHISTÉ, 2008.

Onde: 1- Fonte Luminosa; 2- Recipiente com as amostras; 3- Abertura Frontal; 4Sistema de exaustão; 5- Orifícios de saída de umidade; 6- Calhas para proteção de luminosidade externa e 7- Tela de plástico (escura)

As perdas de cor foram quantificadas por espectrofotometria e colorimetria.

As análises de teor de antocianinas foram realizadas de acordo com o método de Fuleki e Francis (1968) posteriormente revisada por Lees e Francis (1972). Utilizando-se $\mathrm{pH}$ único, alíquotas de $1 \mathrm{~mL}$ de extrato, exposto às diferentes luminosidades, foram diluídas em $9 \mathrm{~mL}$ de etanol $95 \%$ com $\mathrm{HCl}$ 1,5 N (85:15), homogeneizadas e levadas ao espectrofotômetro (UV- Visível, SHIMADZU modelo 160-A).

$\mathrm{O}$ teor de antocianinas foi expresso em $\mathrm{mg}$ de antocianinas $/ 100 \mathrm{~g}$ de fruto. $\mathrm{O}$ cálculo foi efetuado de acordo com a equação 1 .

$T A\left(\frac{m g}{100 \text { g de fruto }}\right)=\frac{A b s \lambda_{\operatorname{má} x} \times F d \times 100}{E_{1 c m}^{1 / 0}}$

Onde: TA é o teor de antocianinas, $\operatorname{Abs}_{\lambda \text { máx }}$ é a absorvância no comprimento de onda máximo; Fd é o fator de diluição e $E_{1 \mathrm{~cm}}^{1 \%}$ é a absorvidade molar a $535 \mathrm{~nm}$ e corresponde a 98,29 em antocianinas de Cramberries. 
Um colorímetro Chroma Meter CR-310 Minolta foi usado para medir as características de cor visível (sistema Hunter Lab) das amostras. $\mathrm{O}$ instrumento foi calibrado antes de cada leitura com um azulejo branco $(Y=93,7, x=0,3161, y=$ 0,3319). As amostras foram colocadas em cubeta de borosilicato cilíndrica de $4 \mathrm{~cm}$ de diâmetro de forma a obter uma película de 1 $\mathrm{cm}$ de extrato, então os parâmetros colorimétricos foram medidos. Os valores de cor foram expressos como L (luminosidade), a (vermelho/verde) e b (amarelo/azul).

Para analisar a cor do extrato antociânico, para cada tipo de lâmpada foram realizadas 19 medições e a cada dado coletado os valores dos fatores $\mathrm{L}, \mathrm{a}$ e $\mathrm{b}$ foram estimados, usando as equações 2,3 e 4 .

$$
\begin{aligned}
\Delta L & =L_{\text {ensaio }}-L_{\text {padrão }} \\
\Delta a & =a_{\text {ensaio }}-a_{\text {padrão }} \\
\Delta b & =b_{\text {ensaio }}-b_{\text {padrão }}
\end{aligned}
$$

O valor da diferença absoluta de cor entre um padrão e uma amostra destas três coordenadas resulta no fator $\Delta \mathrm{E}$, o qual é o responsável pela variação da coloração do corante. Com a equação 5 , pode-se obter os valores correspondentes para cada variação de cor dos extratos antociânicos submetidos a diferentes lâmpadas.

$$
\Delta E=\left[(\Delta L)^{2}+(\Delta a)^{2}+(\Delta b)^{2}\right]^{1 / 2}
$$

Paralelamente, foram realizados os mesmos testes para uma amostra protegida de luz, para que permitisse a comparação entre padrão e as outras amostras.

Tanto a análise de cor como a análise de teor de antocianinas foram feitas em triplicata.

Para analisar a estabilidade do extrato antociânico, foi estimado a ordem aparente da reação, a velocidade da reação de degradação do pigmento $(\mathrm{K})$ e o tempo de meia vida $\left(\mathrm{t}_{1 / 2}\right)$.
Os parâmetros dos modelos cinéticos foram estimados por procedimento iterativo de regressão não-linear utilizando o Software Statistica 7.0.

A Tabela 1 sumariza os três modelos de ordem da reação utilizados na predição dos dados de degradação do pigmento do açaí.

Tabela 1. Modelos utilizados na predição dos dados de degradação do pigmento.

\begin{tabular}{ccr}
\hline $\begin{array}{c}\text { Ordem da } \\
\text { reação }\end{array}$ & Modelos & Referência \\
\hline 0 & $C=C_{o}-k t$ & $\begin{array}{r}\text { Fu e Labuza } \\
(1997)\end{array}$ \\
$1^{\mathrm{a}}$ & $C=C_{o} \exp ^{-k t}$ & Fu e Labuza \\
$(1997)$ \\
$2^{\mathrm{a}}$ & $C=\frac{1}{k t+\frac{1}{C_{o}}}$ & Fu e Labuza \\
& $(1997)$
\end{tabular}

$\mathrm{C}=$ Concentração de antocianinas no tempo t; $\mathrm{C}_{0}=$ Concentração inicial de antocianinas; $\mathrm{k}=$ Constante de velocidade; $\mathrm{t}=$ Tempo.

A estimativa dos tempos de meia-vida para as diferentes ordens de reação cinética foi conduzida de acordo com os modelos descritos na Tabela 2.

Tabela 2 - Tempos de meia-vida para as diferentes ordens de reação.

\begin{tabular}{crr}
\hline $\begin{array}{c}\text { Ordem } \\
\text { da reação }\end{array}$ & $\begin{array}{c}\text { Tempo de } \\
\text { meia vida }\left(\mathrm{t}^{1 / 2}\right)\end{array}$ & Referência \\
\hline 0 & $t_{1 / 2}=\frac{C_{o}}{2 k}$ & $\begin{array}{r}\text { Taoukis, Labuza } \\
\text { e Saguy (1997) }\end{array}$ \\
$1^{\mathrm{a}}$ & $t_{1 / 2}=\frac{\ln 2}{k}$ & $\begin{array}{r}\text { Taoukis, Labuza } \\
\text { e Saguy (1997) }\end{array}$ \\
$2^{\mathrm{a}}$ & $t_{1 / 2}=\frac{1}{k C_{o}}$ & $\begin{array}{r}\text { Taoukis, Labuza } \\
\text { e Saguy (1997) }\end{array}$ \\
\hline
\end{tabular}

$\mathrm{C}_{0}=$ Concentração inicial; $\mathrm{k}=$ Constante $\mathrm{de}$ velocidade; $\mathrm{t}=$ Tempo.

\section{RESULTADOS}




\subsection{Cinética de degradação de antocianinas}

Sabendo-se que a cor do fruto do açaí é primariamente proporcionada pelas antocianinas, é sensato testar a estabilidade luminosa das antocianinas de forma que esta informação possa ser usada no processo de armazenamento. A estabilidade luminosa das antocianinas presentes no açaí foi estudada sob efeito de quatro tipos de lâmpadas, fluorescente (Flu), incandescente (Inc), LED e infravermelho (IV), além do ambiente escuro que serviu padrão (Bra). Os resultados obtidos encontram-se na Tabela 3.

Tabela 3- Teores de antocianinas em função do tempo de exposição a diferentes tipos de lâmpadas.

\begin{tabular}{cccccc}
\hline \multicolumn{5}{c}{ Teor de Antocianinas (mg/100g de fruto) } \\
\cline { 2 - 6 } T (h) & Flu & Inc & Led & IV & Bra \\
\hline 0 & 49,58 & 46,22 & 46,22 & 49,58 & 49,58 \\
12 & 51,70 & 46,77 & 46,19 & 37,15 & 52,21 \\
24 & 49,65 & 45,86 & 46,00 & 15,14 & 49,03 \\
36 & 48,11 & 44,17 & 40,00 & 9,63 & 49,87 \\
48 & 44,07 & 46,34 & 38,00 & 4,81 & 52,05 \\
72 & 38,82 & 38,07 & 35,00 & 2,70 & 52,44 \\
120 & 28,35 & 23,10 & 24,00 & 2,05 & 50,28 \\
168 & 12,94 & 15,96 & 19,44 & 1,95 & 49,93 \\
216 & 10,38 & 9,68 & 15,16 & 2,50 & 44,90 \\
264 & 4,77 & 6,39 & 6,61 & 2,64 & 41,01 \\
312 & 3,31 & 5,13 & 5,05 & - & 42,89 \\
360 & 4,33 & 7,44 & 4,22 & - & 40,04 \\
408 & 3,22 & 3,85 & 3,48 & - & 38,13 \\
456 & 3,29 & 3,14 & 3,03 & - & \\
504 & 2,78 & 3,25 & 2,58 & - & 36,28 \\
552 & 2,98 & 2,82 & 2,47 & - & 30,62 \\
600 & 3,04 & 2,98 & 2,83 & - & 32,72 \\
648 & 4,54 & 3,19 & 2,32 & - & 27,20 \\
696 & 3,17 & 3,34 & 1,81 & - & 27,34 \\
\hline
\end{tabular}

Com base na análise da Tabela 1, observa-se em todos os tipos de lâmpadas comportamento semelhante referente ao decréscimo na concentração de antocianinas com o tempo de exposição à luz. Verifica-se que as maiores variações ocorreram nos primeiros dias de exposição. No caso da lâmpada infravermelha, não foi possível obter informações a respeito do extrato depois do período de $240 \mathrm{~h}$ de experimento devido a demasiada evaporação do mesmo quando exposto à elevada temperatura provocada pela lâmpada $\left(39,5^{\circ} \mathrm{C}\right)$.

A degradação das antocianinas do açaí durante a exposição às diferentes lâmpadas foi plotada em função do tempo (Figura 1).

Figura 1 - Degradação as antocianinas do açaî durante o tempo de exposição a diferentes tipos de lâmpadas.

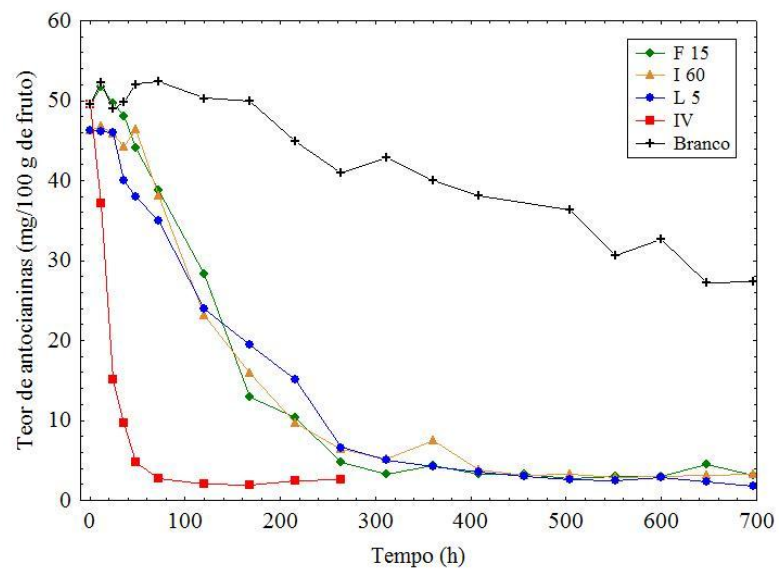

Com base na análise da Figura 1, constata-se uma redução acentuada nos dez primeiros dias de experimento (264 h), com valores de redução do teor de antocianinas de aproximadamente $90,4 \%, 86,2 \%$ e $85,7 \%$ para as lâmpadas Fluorescentes, Incandescentes e LED, respectivamente. $\mathrm{O}$ efeito degradante da incidência luminosa sobre $\mathrm{o}$ extrato antociânico se evidencia quando é observado o comportamento do mesmo extrato quando armazenado protegido de qualquer luminosidade, onde o decréscimo de antocianinas se mostrou em torno de $17,3 \%$. Tal comportamento não se observa na lâmpada infravermelha que apresenta decaimento de $94,7 \%$ em três dias $(72 \mathrm{~h})$. Atribui-se tal resultado ao agravante da elevada temperatura proporcionada por este tipo de lâmpada. Patras et al. (2010) afirmam que tanto a magnitude quanto a duração do 
aquecimento têm forte influência na estabilidade de antocianinas.

É claro pela Figura 2 que a degradação luminosa das antocianinas do açaí seguiu a cinética de reação de primeira ordem no que diz respeito aos diferentes tipos de lâmpadas.

Figura 2 - Teores de antocianinas em função do tempo de exposição à diferentes lâmpadas.

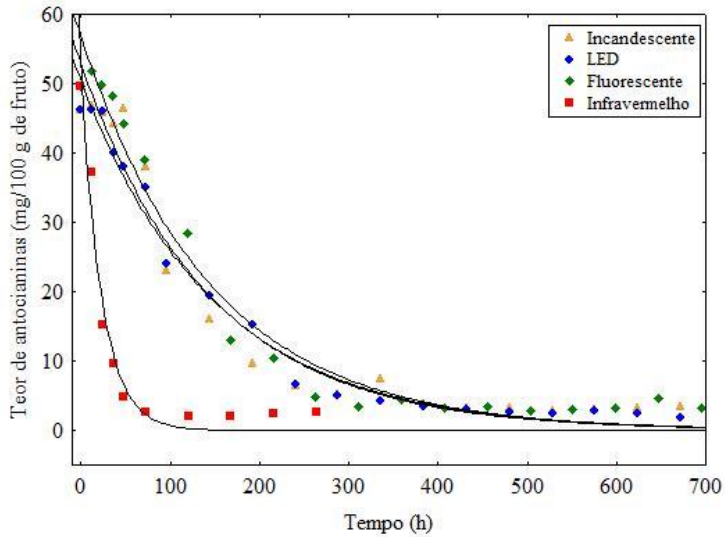

Um comportamento semelhante foi obtido por Melo, Costa e Faria (2001) e Chisté (2008) no estudo de fotodegradação de bixina extraída de sementes de urucum e do extrato antociânico obtido da casca de mangostão, respectivamente.

Observa-se, na Figura 2, que todas as lâmpadas testadas, à exceção da infravermelha, apresentaram comportamento cinético de degradação do corante contido nos frutos de açaí similar para diferentes potências.

As constantes de reação e as concentrações iniciais para cada tipo de lâmpada testado, além do branco, assim como os parâmetros de ajuste utilizados para avaliar os modelos matemáticos que descrevem a cinética de degradação do pigmento de açaí estão mostradas na Tabela 4.

Por meio da análise dos dados da Tabela 4 constata-se que a fotodegradação do extrato de antocianinas do açaí pode ser descrita por uma reação de primeira ordem, com base na estatística $\mathrm{R}^{2}$ e na análise dos resíduos gerados pelo modelo de primeira ordem. A escolha foi devida esse modelo apresentar comparativamente os maiores valores do coeficiente de determinação $\left(\mathrm{R}^{2}>\right.$ 0,96) e distribuição dos resíduos aleatória em função dos valores preditos para a concentração de antocianinas, para todas as lâmpadas. Também, somente para o modelo de primeira ordem, foram satisfeitos os pressupostos estatísticos de independência, normalidade e homogeneidade de variâncias.

Tabela 4- Parâmetros cinéticos para o extrato antociânico exposto a incidência direta de diferentes tipos de lâmpadas.

\begin{tabular}{cccccc} 
Lâmpada & OR & $\mathbf{C}_{\mathbf{0}}$ & $\mathbf{k}$ & $\mathbf{R}^{2}$ & DR \\
& & & & & \\
\hline \multirow{3}{*}{ Branco } & 0 & 52,64 & 0,036 & 0,976 & $\mathrm{~A}$ \\
& $1^{\text {a }}$ & 53,21 & 0,001 & 0,967 & $\mathrm{~A}$ \\
& $2^{\text {a }}$ & 53,50 & 0,000 & 0,953 & $\mathrm{~T}$ \\
\hline \multirow{3}{*}{ Flu } & 0 & 40,73 & 0,074 & 0,856 & $\mathrm{~T}$ \\
& $1^{\text {a }}$ & 56,69 & 0,007 & 0,986 & $\mathrm{~A}$ \\
& $2^{\text {a }}$ & 60,05 & 0,000 & 0,952 & $\mathrm{~T}$ \\
\hline \multirow{3}{*}{ LED } & 0 & 37,04 & 0,069 & 0,884 & $\mathrm{~T}$ \\
& $1^{\text {a }}$ & 50,37 & 0,007 & 0,993 & $\mathrm{~A}$ \\
& $2^{\text {a }}$ & 54,36 & 0,000 & 0,963 & $\mathrm{~A}$ \\
\hline \multirow{3}{*}{ Inc } & 0 & 38,06 & 0,070 & 0,856 & $\mathrm{~T}$ \\
& $1^{\text {a }}$ & 52,76 & 0,007 & 0,979 & $\mathrm{~A}$ \\
& $2^{\text {a }}$ & 56,03 & 0,000 & 0,947 & $\mathrm{~A}$ \\
\hline \multirow{3}{*}{ IV } & 0 & 24,02 & 0,117 & 0,636 & $\mathrm{~T}$ \\
& $1^{\text {a }}$ & 51,73 & 0,043 & 0,984 & $\mathrm{~A}$ \\
& $2^{\text {a }}$ & 51,63 & 0,002 & 0,958 & $\mathrm{~T}$ \\
\hline
\end{tabular}

$\mathrm{OR}=$ Ordem da reação; $\mathrm{C}_{0}=$ Concentração inicial ( $\mathrm{mg}$ de antocianinas $/ 100 \mathrm{~g}$ de fruto); $\mathrm{k}=$ Constante de velocidade da reação $\left(h^{-1}\right), R^{2}=$ coeficiente de determinação; $\mathrm{DR}=$ Distribuição dos resíduos; $\mathrm{T}=$ tendenciosa; $\mathrm{A}=$ aleatória (desejada).

De posse do valor da constante de velocidade de degradação, é possível calcular o tempo de meia-vida do extrato antociânico de açaí. O cálculo foi feito utilizando as equações da Tabela 2 de acordo com o modelo que melhor descreve o processo de fotodegradação. $\mathrm{Na}$ Tabela 5, estão representados os valores obtidos. 
A análise da Tabela 5 comprova que a amostra submetida à incidência de luz LED teve maior tempo de meia-vida entre as demais amostras. Esta perdeu $50 \%$ da concentração inicial depois de 103,75 horas.

Tabela 5. Efeito do tipo da lâmpada no tempo de meia-vida do extrato antociânico de açaí.

\begin{tabular}{cc}
\hline Lâmpadas & $\begin{array}{c}\text { Tempo de meia-vida } \\
\left(\mathrm{t}_{1 / 2}\right) \text { (horas) }\end{array}$ \\
\hline Flu & 101,19 \\
LED & 103,75 \\
Inc & 99,96 \\
IV & 16,07 \\
\hline
\end{tabular}

Chisté (2008) verificou que o extrato antociânico de mangostão teve tempos de meia-vida de 597,54 h, 306,7 h e 100,02 h para as lâmpadas fluorescente, incandescente e infravermelha, respectivamente. Já Lima, Melo e Lima (2005) estudaram a degradação do extrato antociânico de pitanga roxa, frente à luminosidade fluorescente e concluíram que a perda de $50 \%$ da cor original ocorre após 948 h. Esta diferença de suscetibilidade dos extratos antociânico ao efeito estresse luminoso pode ser devido a variada composição de antocianidinas característica de cada uma das frutas.

\section{$\underline{3.2}$ Colorimetria Tri-estímulo}

As Figuras 4, 5, 6 e 7 ilustram as mudanças de coloração apresentadas pelo extrato antociânico quando submetido à incidência de diferentes lâmpadas. No qual, valores de L representam a luminosidade, ou seja, a capacidade de um objeto refletir ou transmitir luz, resultando em uma cor luminosa (100 - branco) ou escura (zero preto); a é a coordenada de cromaticidade que indica a variação de tonalidade de vermelho ao verde (valor positivo representa vermelho e negativo, verde) e b a coordenada oscila de amarelo a azul (valor positivo representa amarelo e negativo, azul).
A Figura 3 demonstra o perfil que o extrato deveria seguir se as lâmpadas incidentes não tivessem considerável influência na degradação do corante.

Com base na análise das Figuras 4, 5, 6 e 7, e comparando-os com a Figura 3, que foi observado em condições normais, sem a influência de luzes, observa-se um acréscimo no fator L, comprovando analiticamente o que também foi observado visualmente: que a luminosidade do corante aumentou com o passar do tempo de armazenamento sob incidência direta de luz, tendendo cada vez mais à tonalidade clara.

Figura 3- Parâmetros colorimétricos do corante de açaí protegido da luz (branco).

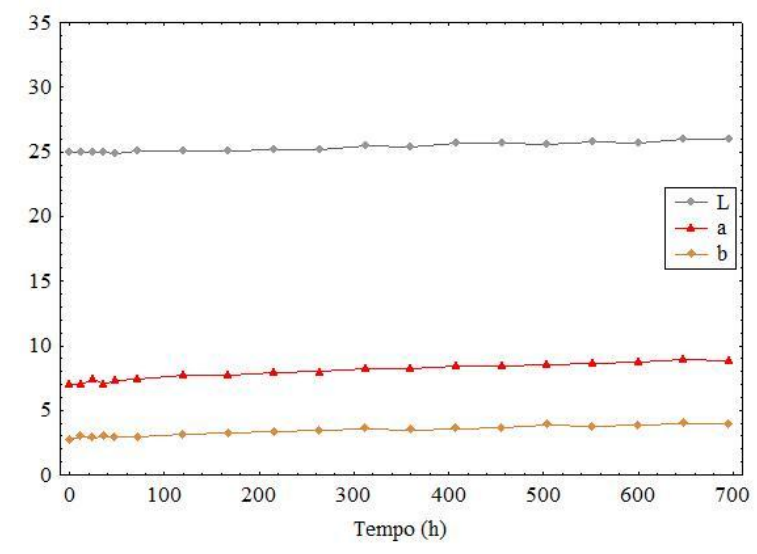

Figura 4- Parâmetros colorimétricos do corante de açaí exposto à lâmpada fluorescente.

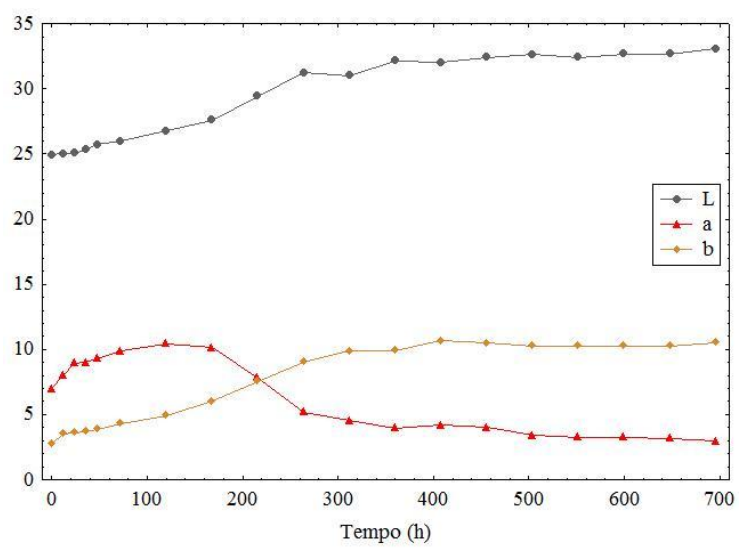


Figura 5- Parâmetros colorimétricos do corante de açaí exposto à lâmpada LED.

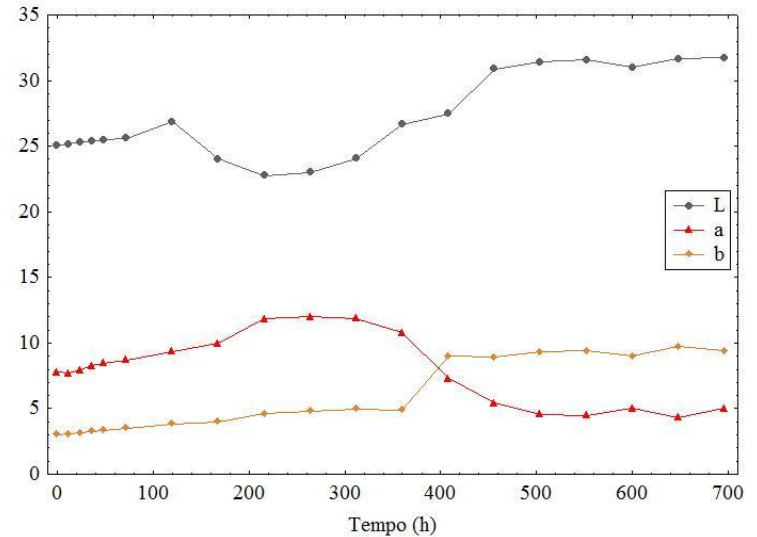

Figura 6- Parâmetros colorimétricos do corante de açaí exposto à lâmpada incandescente.

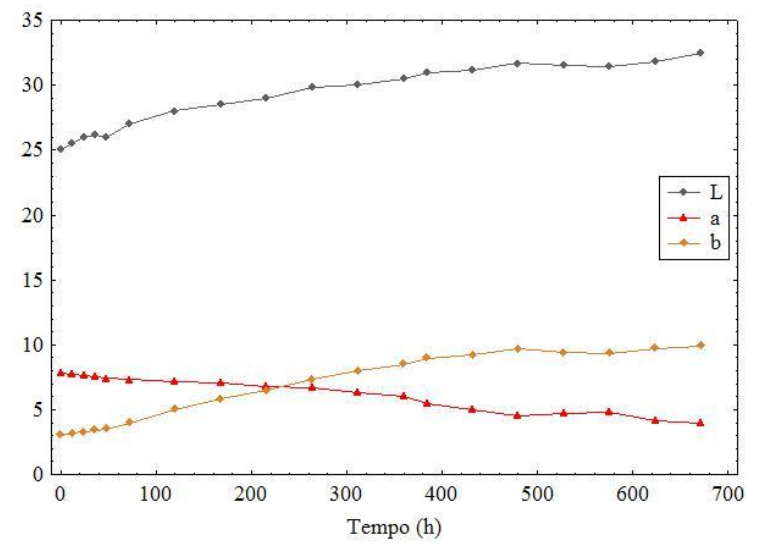

Figura 7- Parâmetros colorimétricos do corante de açaí exposto à lâmpada infravermelha.

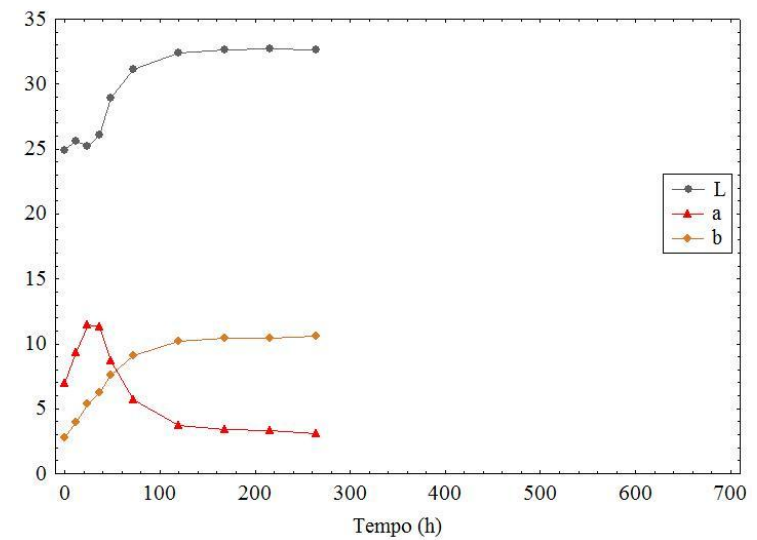

Já a coordenada a indicou que o extrato antociânico tende cada vez mais a deixar a coloração vermelha, e o fator $b$ deixou comprovado que a tonalidade amarela estava se intensificando, dando ao extrato uma coloração vermelho-amarelado.

A partir dos resultados obtidos observou-se que todas as lâmpadas estudadas, exerceram maior influência no corante nas primeiras horas de incidência. Notou-se que até aproximadamente 400 horas de exposição do extrato à luminosidade, este sofreu grande alteração na sua coloração, porém a partir deste ponto não se observou variação significativa. Comprovando assim, que a incidência de luz constante altera a coloração final desejável.

$\mathrm{Na}$ Figura 8 podem ser observadas as colorações alcançadas dos extratos antociânicos antes e depois do ensaio de degradação para cada um dos tipos de lâmpada testados.

Figura 8 - Efeito degradante de diferentes tipos de lâmpada sobre o extrato antociânico de açaí após 30 dias.

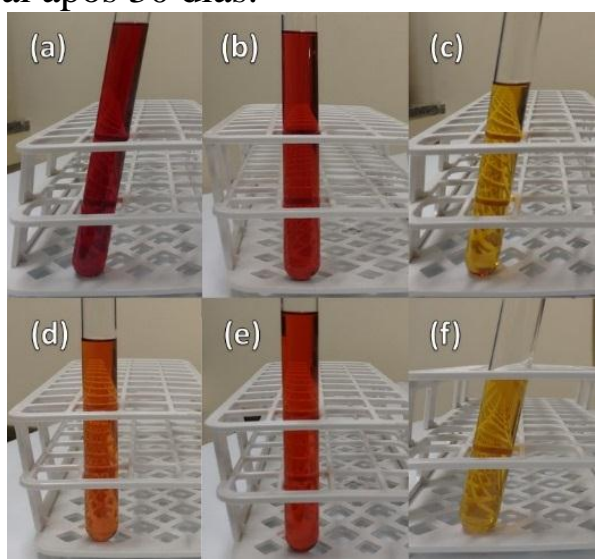

(a) Extrato de açaí antes do processo degradativo;

(b) Branco; (c) Fluorescente; (d) Incandescente;

(e) LED; (f) Infravermelho.

De acordo com o sistema Hunter Lab, os valores obtidos através da Equação 5, demonstraram que a coloração sofreu alterações de acordo com os valores obtidos 
para $\Delta \mathrm{E}$, os quais encontram-se na tabela 6 .

As maiores variações de cor $(\Delta \mathrm{E})$ encontradas para as lâmpadas fluorescente, LED, incandescente e infravermelho foram de $11,95,9,65,10,83$ e 12,59, respectivamente. Comparando-se com a amostra padrão, verificamos que o corante perdeu muito da sua tonalidade inicial. Deixando assim de possuir a coloração característica do açaí.

Tabela 6- Diferenças de cor no sistema Hunter $\mathrm{L}$ a b, em função de $\Delta \mathrm{E}$, nos diferentes tipos de lâmpadas.

\begin{tabular}{cccccc}
\hline \multirow{2}{*}{$\mathbf{t}(\mathbf{h})$} & \multicolumn{5}{c}{$\Delta \mathbf{E}$} \\
\cline { 2 - 6 } & BRA & FLU & LED & INC & IV \\
\hline 0 & 26,04 & 26,04 & 26,40 & 26,40 & 26,04 \\
12 & 0,23 & 1,27 & 0,17 & 0,50 & 2,70 \\
24 & 0,45 & 2,15 & 0,35 & 1,02 & 5,21 \\
36 & 0,24 & 2,27 & 0,61 & 1,25 & 5,69 \\
48 & 0,35 & 2,69 & 0,87 & 1,14 & 6,50 \\
72 & 0,49 & 3,44 & 1,18 & 2,24 & 8,94 \\
120 & 0,85 & 4,47 & 2,54 & 3,60 & 11,01 \\
168 & 0,91 & 5,25 & 2,60 & 4,48 & 11,45 \\
216 & 1,11 & 6,62 & 4,90 & 5,35 & 11,53 \\
264 & 1,21 & 9,06 & 4,98 & 6,48 & 11,66 \\
312 & 1,61 & 9,67 & 4,60 & 7,17 & 11,80 \\
360 & 1,48 & 10,61 & 3,85 & 7,93 & 12,05 \\
408 & 1,80 & 10,96 & 6,44 & 8,70 & 12,11 \\
456 & 1,86 & 11,15 & 8,61 & 9,12 & 10,99 \\
504 & 2,01 & 11,33 & 9,52 & 9,93 & 11,08 \\
552 & 2,13 & 11,22 & 9,71 & 9,57 & 12,53 \\
600 & 2,20 & 11,40 & 8,89 & 9,46 & 12,45 \\
648 & 2,54 & 11,45 & 10,03 & 10,19 & 12,67 \\
696 & 2,39 & 11,95 & 9,65 & 10,83 & 12,59 \\
\hline
\end{tabular}

Kara e Erçelebi (2013), afirmam ser possível relacionar o parâmetro de cor $\Delta \mathrm{E}$ com o teor de antocianinas do extrato de forma linear, de forma que os parâmetros Hunter de cor podem inclusive substituir a análise espectrofotométrica.

Lima, Melo e Lima (2005) fizeram este estudo para a estabilidade da pitanga roxa e constataram a perda de $50 \%$ da cor inicial após 948,3h (39 dias) para o extrato submetido ao efeito da luz e após 1205,7h (50 dias) para o extrato ao abrigo da luz, demonstrando a maior instabilidade da antocianina quando exposta à luminosidade.

\section{CONCLUSÃO}

A degradação do extrato antociânico de açaí durante a exposição à diferentes tipos de estresse luminoso seguiu a cinética de reação de primeira ordem.

Pôde ser constatado um decréscimo significativo dos teores de antocianinas em exposição direta a diferentes tipos de lâmpada em um decorrer de tempo. Constatou-se também que este decrescimento ocorreu de forma mais significativa nas primeiras horas de exposição, comprovando assim que o extrato antociânico é muito sensível a luz e sua exposição direta a esta, acelera sua degradação.

O efeito degradante das lâmpadas fluorescente, incandescente e LED sob o extrato antociânico de açaí foi similar apesar da divergência de natureza e potência.

Em termos de tempo de meia vida do corante contido no extrato antociânico, à exceção da lâmpada infravermelha, todos os tipos de lâmpada testados apresentaram resultado aproximado, o que permite afirmar que estes tipos de lâmpada nas potências selecionadas têm o mesmo efeito sobre o extrato de açaí. Entretanto, dentre os diferentes tipos de luz incidente, a que apresentou melhor resultado foi a de LED, à qual conseguiu manter as características iniciais por um período de tempo maior, demostrando assim sua maior eficiência.

\section{REFERÊNCIAS}

ALEXANDRE， D.; CUNHA， R.; HUBINGER, M. Conservação do açaí pela tecnologia de obstáculos. Ciência Tecnologia de Alimentos, v.24, n.1, p.114-119, 2004.

CHISTÉ, R. C. Estabilidade do Extrato Antociânico Obtido da Casca do Mangostão (Garcinia mangostana L.). 2008. 106p. Dissertação (Mestrado em Ciência e 
Tecnologia de Alimentos) - Universidade Federal do Pará, Belém.

CONSTANT, P. B. L. Extração, caracterização e aplicação em antocianinas de açaí. 2003. 199p. Tese (Doutorado em Ciência e Tecnologia de Alimentos) Universidade Federal de Viçosa, Viçosa.

FULEKI, T.; FRANCIS, F. J. Quantitative methods for anthocyanins. 1 Extraction and determination of total anthocyanin in craberries. Journal of Food Science, v.33, p.72- 77, 1968.

FU, B.; LABUZA, T. P. Shelf life of frozen foods. In: LABUZA, T. P.; FU, B. Denver: CRC Press, 1997. Cap. 19. p.377415.

KARA, S.; ERÇELEBI, E. A. Thermal degradation kinetics of anthocyanins and visual colour of Urmu mulberry (Morus nigra L.). Journal of Food Engineering, v.116, p.541-547, 2013.

LEES, D. H.; FRANCIS, F. G. Standardization of pigment analysis in cramberries. Hortscienc, [S.I.], v.7, p. 83-84, 1972.

LIMA, V.L.A.G.; MÉLO, E.A.; LIMA, D.E.S. Efeito da Luz e da Temperatura de Congelamento Sobre a Estabilidade das Antocianinas da Pitanga Roxa. Campinas, 2005.

MELO, K. P.; COSTA, C. M. L.; FARIA, L. J. G. Análise da Cinética de fotodegradação de bixina contida em sementes de urucum (Bixa Orellana L.). Revista Brasileira de Corantes Naturais (SBCN), Campina Grande, v.5, p.79-85, 2001.

PATRAS, A., BRUNTON, N.P., O'DONNELL, C., TIWARI, B.K. Effect of thermal processing on anthocyanin stability in foods; mechanisms and kinetics of degradation. Trends in Food Science and Technology, 21, p. 3-11, 2010.

SOUSA, M. A. C.; YUYAMA, L. K. O.; AGUIAR, J. P. L., PANTOJA, L. Suco de açaí (Euterpe oleracea Mart.): avaliação microbiológica, tratamento térmico e vida de prateleira. Acta Amazonica, v.36, n.4, p. 483 - 496, 2006.

TAOUKIS, P. S.; LABUZA, T. P.; SAGUY, I. S. Kinetics of food deterioration and shelf-life prediction. In: VALENTAS, ÊK. J.; ROTSTEIN,ÊE.; SINGH,ÊR. P. . Boca Raton:ÊCRC Press LLC, 1997. p.361-402 